\title{
Efficacy and safety of direct-acting antiviral therapy in previous hard-to-treat patients with recurrent hepatitis $C$ virus infection after liver transplantation: a real-world cohort
}

\author{
This article was published in the following Dove Press journal: \\ Drug Design, Development and Therapy \\ 12 July 2017 \\ Number of times this article has been viewed
}

\author{
Sebastian Bernuth' \\ Daniel Grimm' \\ Johanna Vollmar' \\ Felix Darstein' \\ Jens Mittler ${ }^{2}$ \\ Michael Heise ${ }^{2}$ \\ Maria Hoppe-Lotichius ${ }^{2}$ \\ Peter R Galle' \\ Hauke Lang ${ }^{2}$ \\ Tim Zimmermann' \\ 'First Department of Internal \\ Medicine, Transplant Hepatology, \\ ${ }^{2}$ General-, Abdominal- and Transplant- \\ Surgery, University Medical Center, \\ Johannes Gutenberg University, \\ Mainz, Germany
}

\begin{abstract}
Background: Recurrent hepatitis $\mathrm{C}$ virus (HCV) infection after liver transplantation (LT) has been a frequent and relevant problem in the past two decades. This analysis evaluated the efficacy and safety of new interferon (IFN)-free direct-acting antiviral (DAA) therapies in a large real-world cohort of HCV patients after LT.

Methods: We retrospectively analyzed a cohort of 157 patients infected with $\mathrm{HCV}$ who underwent deceased donor LT between 1997 and 2014. Patient survival, outcome, and side effects of antiviral therapy were assessed.

Results: Survival with recurrent HCV genotype 1 (GT1) infection was inferior to other HCV GTs $(P=0.01)$. The overall sustained virological response (SVR) rate with new DAA therapy was $94.6 \%(n=37)$. Patients with both GT1 and other GTs reached SVR rates $>90 \%$. We noticed a few side effects, mainly caused by ribavirin, and only one discontinuation in DAA-treated patients. Conclusion: DAA therapy was effective and safe in previous hard-to-treat patients after LT in this real-world cohort.
\end{abstract}

Keywords: HCV, DAA, liver transplantation, reinfection, sustained virological response, SVR

\section{Introduction}

Hepatitis $\mathrm{C}$ virus (HCV) infection is a leading cause of end-stage liver disease and hepatocellular carcinoma (HCC). ${ }^{1}$ Approximately $25 \%$ of primary $\mathrm{HCC}$ and $25 \%$ of liver cirrhosis are caused by chronic hepatitis C. ${ }^{2}$ Thus, HCV-related liver failure and $\mathrm{HCC}$ have been the most frequent indications for liver transplantation (LT) in Western countries in the past two decades. ${ }^{3} \mathrm{HCV}$ infection itself cannot be cured by LT, and graft reinfection universally occurs. ${ }^{4,5}$ Fibrosis progression after LT is accelerated under immunosuppressive therapy with high rates of $\mathrm{HCV}$-associated recurrent cirrhosis. ${ }^{6}$ In $\mathrm{HCV}$-infected recipients, the development of decompensated recurrent cirrhosis is the leading cause of graft failure, patient death, and the need for retransplantation. ${ }^{4,6-11}$ Antiviral treatment with pegylated interferon (PEG-IFN) was the standard of care in transplant recipients with recurrent hepatitis C. After transplantation, sustained virological response (SVR) rates ranged between 26 and 50\%. ${ }^{12}$ With the approval of new direct-acting antivirals (DAAs), the management of recurrent $\mathrm{HCV}$ infection has greatly improved.

In 2014, the first NS5B RNA-polymerase inhibitor sofosbuvir (SOF) became available for the treatment of $\mathrm{HCV}$-infection in combination with PEG-IFN and/or
Correspondence: Tim Zimmermann First Department of Internal Medicine, Transplant Hepatology, Interdisciplinary Transplant Center, University Medical Center, Johannes Gutenberg University, Langenbeckstr I, 55I0I Mainz, Germany Tel +49 6I3। I7 3980

Fax +49613117476075

Email tim.zimmermann@unimedizinmainz.de 
ribavirin (RBV), yielding high SVR rates in non-LT and LT patients. ${ }^{13,14}$ However, there is only a limited database for its use in LT recipients, and especially a gap prevails in clinical real-world data. ${ }^{15-18}$

The indication for antiviral treatment of recurrent hepatitis C was usually based on the first evidence of acute allograft injury by a significant increase in serum alanine aminotransferase (ALT) and HCV-RNA levels or when the patient had histological evidence of established liver disease, with inflammation and/or fibrosis ( $\geq$ F2) of the graft. ${ }^{19,20}$ Due to IFN-associated side effects and RBV-induced anemia, antiviral treatment of $\mathrm{HCV}$ infection after LT is challenging. Treatment-associated rejection episodes and a flare of liver disease may have resulted in graft failure and ultimately in patient death. ${ }^{12,21,22}$ With the approval of DAAs, standard of care has changed to a combination therapy with DAAs, in the beginning in combination with PEG-IFN and RBV. ${ }^{23,24}$ However, experience on post-LT treatment with DAA therapy in real-world cohorts is limited.

We retrospectively analyzed a well-characterized realworld cohort of $\mathrm{HCV}$ patients for genotype, IFN-based pretreatment, outcomes, and survival. A high proportion of these patients were previous non-responders to IFN-based therapy and, therefore, hard to treat. Those patients who underwent DAA treatment were analyzed prospectively.

The aim of this work was to analyze the survival of HCV-positive patients post-LT and investigate the efficacy and safety of DAAs in a real-world cohort of previous hardto-treat LT patients with recurrent hepatitis C.

\section{Patients and methods}

\section{Patient cohort and data collection}

We reviewed a total of 570 patients who underwent deceased donor orthotopic LT between 1997 and 2014 in a singlecenter retrospective analysis. Patients were diagnosed and followed up in the Interdisciplinary Transplant Center at the University Medical Center Mainz, Germany. In total, $157 \mathrm{HCV}$-positive patients were analyzed retrospectively, $72.6 \%$ of whom showed genotype 1 (GT1). Baseline characteristics, previous antiviral treatment, outcomes, and side effects were assessed.

Patients with advanced disease received preferential DAA treatment from 2014 to 2016 : 44 patients were identified with a treatment indication by positive HCV-RNA, 37 of whom received DAA therapy in the meantime. In seven patients, no DAA therapy was performed due to end-stage kidney disease $(n=3)$, recurrence of $\mathrm{HCC}(n=3)$, or non-smallcell lung cancer $(n=1)$.
For the 37 DAA-treated patients, data at baseline, end of treatment (EoT), and 12 weeks after EoT (SVR12) were collected prospectively and analyzed. Taken together, the analysis of all 157 post-transplant patients, eg, overall survival and treatment success of previous therapies, was retrospective. The observation of the $37 \mathrm{DAA}$ patients was prospective. Detailed information about the selection of the study cohort is presented in Figure 1.

\section{Antiviral treatment regimens}

DAA treatment regimens were selected by experienced transplant hepatologists according to the recommendations on treatment of hepatitis C of the European Association for the Study of the Liver (EASL) in the version of 2014 and 2015 depending on the start of therapy. ${ }^{25,26}$ Predictors (cirrhosis, genotype), drug-drug interactions (DDI), especially with different immunosuppressive regimens, and RBV-associated side effects were taken into account as published. ${ }^{24}$ Comedication was checked for DDI online (www.hepdruginteractions. org) and changed to non-interacting alternatives, if necessary. The dose of RBV was adapted according to the manufacturer's instruction.

\section{Biochemical and virological response}

The viral load (HCV-RNA) was assessed at baseline, EoT, and SVR12. We defined virological response as the absence of detectable HCV-RNA at time point SVR12.

The lower limit of HCV-RNA detection is $10 \mathrm{IU} / \mathrm{mL}$ in our laboratory (COBAS TaqMan HCV test, version 2.0; Roche Diagnostics AG, Rotkreuz, Switzerland; lower limit of quantification: $25 \mathrm{IU} / \mathrm{mL}$; lower limit of detection $10 \mathrm{IU} / \mathrm{mL})$.

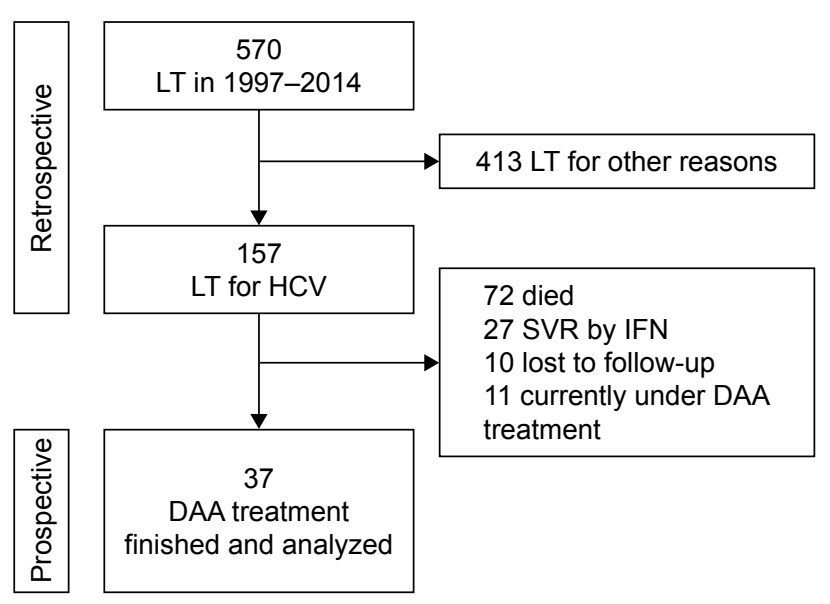

Figure I Flowchart showing the selection of the treatment cohort. Abbreviations: LT, liver transplantation; HCV, hepatitis C virus; DAA, directacting antiviral; SVR, sustained virological response; IFN, interferon. 
Anemia was defined as hemoglobin $(\mathrm{Hb})$ levels $<13.5 \mathrm{~g} / \mathrm{dL}$ and $<12.0 \mathrm{~g} / \mathrm{dL}$ for male and female patients, respectively, according to our laboratory reference ranges and the clinical routine. All clinical chemical parameters were measured by the Central Laboratory of Mainz University Medical Center.

\section{Survival analysis}

We assessed the survival of patients in the first 5 years after LT with and without HCV and differences in GTs after IFNbased antiviral treatment. These long-term follow-up data are not available for DAA-treated patients after LT to date; therefore, a direct comparison between IFN- and DAA-based treatment regimens was not feasible.

\section{Fibrosis assessment}

Liver biopsies in our transplant center are routinely performed 1, 5, and 10 years after LT. Additional biopsies were performed whenever a biochemical or clinical abnormality with signs of graft dysfunction occurred. FibroScan was not routinely performed in all patients since liver biopsies as gold standard were available.

\section{Statistical analysis}

Data are given as medians with corresponding interquartile ranges and shown graphically by box and whiskers plots. Pairwise comparisons of laboratory parameters between baseline and SVR12 were conducted using the nonparametric Wilcoxon signed-rank test. Overall survival was analyzed and graphically presented by Kaplan-Meier curves. Survival between groups was compared by the log-rank test. MannWhitney $U$ test or Kruskal-Wallis test were used to identify significant differences between groups with different treatment regimens or different GTs. $P$-values $<0.05$ were considered as statistically significant. Statistical analyses were performed using SPSS version 22 (SPSS Inc., Chicago, IL, USA).

Data were prospectively collected in our institutional transplant database and retrospectively analyzed. Patients signed informed consent for recording and analyzing of data and agreed to the forwarding or publishing of data in a pseudoor anonymized way. This research was approved by the local ethics committee of Rhineland-Palatinate and was conducted according to the ethical guidelines of the Declaration of Helsinki 1975 and Good Clinical Practice guidelines.

\section{Results}

\section{Baseline characteristics}

Most patients $(72 \%, \mathrm{n}=113)$ were pretreated with IFN-based HCV-therapy: $49.6 \%$ once, $30.9 \%$ twice, and $19.5 \%$ thrice or more. In total, only $23.9 \%$ reached SVR with PEG-IFN and RBV (GT1: 15\%, GT2: 57.1\%, GT3: 64.7\%). Twenty-seven patients completed IFN therapy successfully, 72 died, 10 were lost to follow-up, and in 11 patients DAA therapy will be finished after the observation period (Figure 1).

\section{Survival under IFN-based therapy}

Survival of HCV-positive LT patients $(\mathrm{n}=157)$ under IFNbased therapy was significantly worse compared to patients transplanted for other liver diseases $(P=0.04$, Figure $2 \mathrm{~A})$;
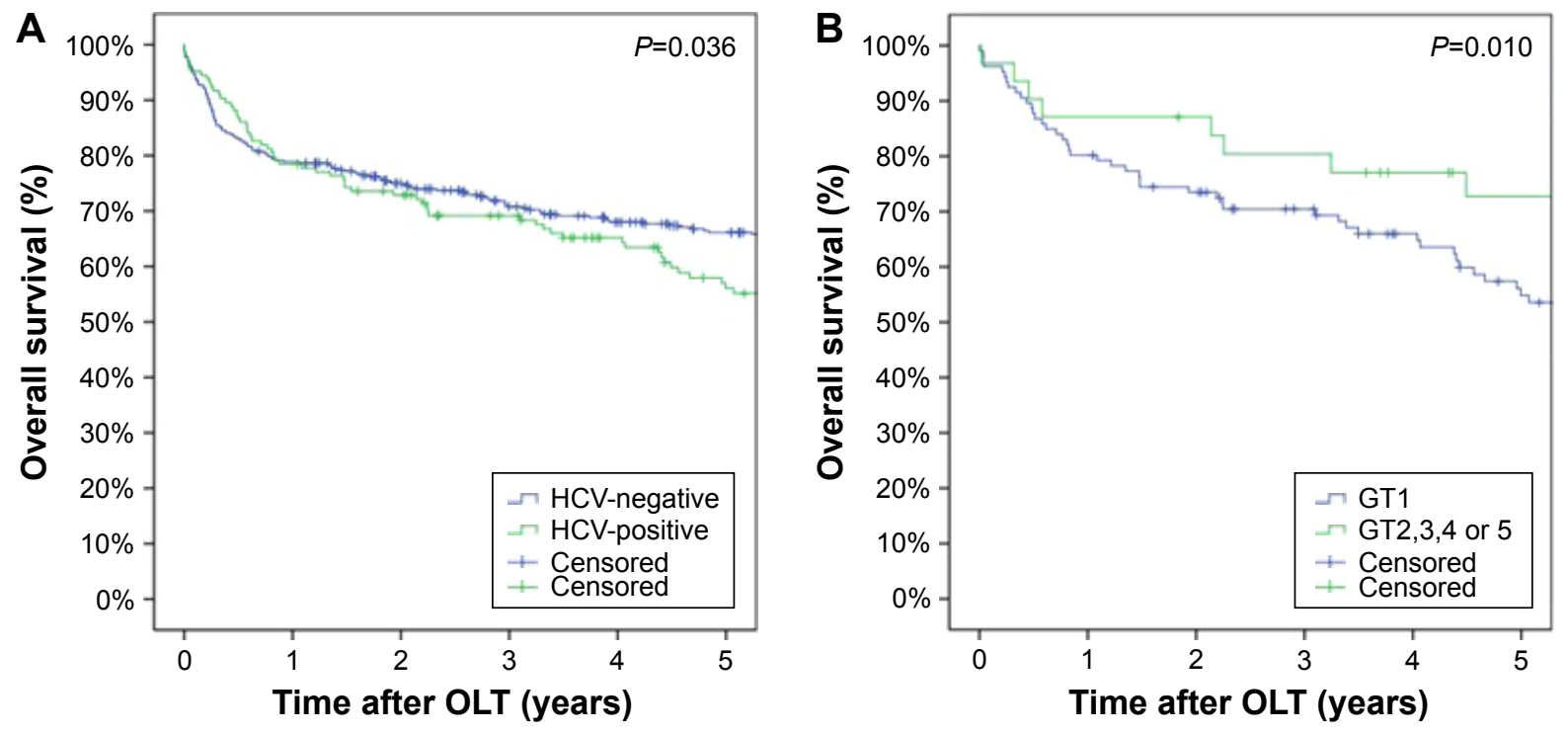

Figure 2 Survival of patients after liver transplantation with or without HCV (A) and GTI vs non-GTI (B). Abbreviations: HCV, hepatitis C virus; OLT, orthotopic liver transplantation; GT, genotype. 
72 of the $157 \mathrm{HCV}$-positive patients (45.9\%) died during follow-up. In 37 cases, death was caused by HCV-induced recurrent cirrhosis $(n=23)$ or recurrent $\operatorname{HCC}(n=14)$.

Almost three-quarters $(72.6 \%, n=114)$ of all the 157 HCV-infected patients showed GT1, 36 (22.9\%) showed GT other than 1, and in seven patients (4.5\%) a GT was not available. Detailed analysis revealed that survival was significantly worse in individuals infected with HCV GT1 $(n=114)$ than in those infected with other HCV GTs $(n=36$, $P=0.01$, Figure $2 \mathrm{~B}$ ).

\section{DAA regimens}

Patients eligible for DAA therapy were identified (Figure 1). In total, 37 recipients started a DAA-based therapy in 2014 and 2015. Only nine patients were therapy naïve but the majority $(n=28)$ failed previous treatment with PEG-IFN and RBV. The median age of the 37 patients treated with DAAs was 59.8 years (57-66), 73\% were male, 13.5\% showed severe fibrosis or cirrhosis, and the median MELD (model for end-stage liver disease) score was 8 (7-11). Antiviral DAA-based therapy was initiated at a median value of 4.9 years (1.1-7.9) after LT. Genotypes were distributed as follows: $67.6 \%$ were infected with HCV GT1, 5.4\% with GT2, 21.6\% with GT3, 2.7\% with GT4, and 2.7\% with GT5. Detailed baseline characteristics and key laboratory values are presented in Table 1.

Of the 37 DAA-treated patients, 36 received SOF, 17 ledipasvir (LDV), eight daclatasvir, two simeprevir, and one 3D regimen with paritaprevir/ritonavir/ombitasvir and dasabuvir. Three patients were treated in combination with IFN and 20 patients received RBV. Detailed treatment regimens are shown in Figure 3. The treatment duration was 12 weeks (23 patients, $62.2 \%$ ) or 24 weeks (14 patients, $37.8 \%)$. Genotypes were distributed as expected for Germany (GT1: 67.6\%; non-GT1: 32.4\%).

\section{Virological response}

In total, $94.6 \%(\mathrm{n}=35)$ reached SVR by DAA therapy. In detail, $96 \%$ of GT $1,100 \%$ of GT2, $87.5 \%$ of GT3, $100 \%$ of GT $4 / 5$ patients had no detectable HCV-RNA 12 weeks after EoT, and did not show any significant differences $(P=0.932)$. Patients treated with or without RBV $(89.5 \%$ vs $100 \%, P=0.619)$ and patients treated for 12 or 24 weeks $(95.7 \%$ vs $95.9 \%, P=0.889)$ showed similar SVR rates without any significant differences.

\section{Biochemical response}

The biochemical response to DAA therapy is shown in Figure 4. In particular, the serum activities for ALT (44.5-21.5 IU/L), aspartate aminotransferase (AST; 45.0-30.0 IU/L),
Table I Patient demographics at baseline (quantitative data are given as medians and interquartile range in parentheses)

\begin{tabular}{|c|c|}
\hline Characteristics & Overall \\
\hline Sample size & $\mathrm{n}=37$ \\
\hline Male & $73.0 \%(n=27)$ \\
\hline Age & 59.8 years $(57.1-66.2)$ \\
\hline Time since OLT & 4.9 years $(1 . I-7.9)$ \\
\hline \multicolumn{2}{|l|}{ HCV genotype } \\
\hline $\mathrm{I}$ & $67.6 \%(n=25)$ \\
\hline 2 & $5.4 \%(n=2)$ \\
\hline 3 & $21.6 \%(n=8)$ \\
\hline 4 & $2.7 \%(n=I)$ \\
\hline 5 & $2.7 \%(n=I)$ \\
\hline \multicolumn{2}{|l|}{ Treatment regimen } \\
\hline IFN & $8.1 \%(n=3)$ \\
\hline RBV & $51.4 \%(n=24)$ \\
\hline SOF & $97.3 \%(n=36)$ \\
\hline SMV & $5.4 \%(n=2)$ \\
\hline LDV & $45.9 \%(n=17)$ \\
\hline DCV & $21.6 \%(n=8)$ \\
\hline $3 D$ & $2.7 \%(n=1)$ \\
\hline \multicolumn{2}{|l|}{ Duration of treatment } \\
\hline 12 weeks & $62.2 \%(n=23)$ \\
\hline 24 weeks & $37.8 \%(n=\mid 4)$ \\
\hline \multicolumn{2}{|l|}{ Stage of fibrosis } \\
\hline From no to mild ( $\leq \mathrm{F} 2)$ & $86.5 \%(n=32)$ \\
\hline Severe $(\geq F 3)$ & $13.5 \%(n=5)$ \\
\hline MELD score & $8(7-11)$ \\
\hline HCV-RNA & $2.2 \times 10^{6} \mathrm{IU} / \mathrm{mL}\left(1.0 \times 10^{6}\right.$ to $\left.5.5 \times 10^{6}\right)$ \\
\hline Bilirubin & $0.78 \mathrm{mg} / \mathrm{dL}(0.63-1.02)$ \\
\hline Hemoglobin & $13.7 \mathrm{~g} / \mathrm{dL}(\mid 1.8-15.0)$ \\
\hline ALT & $44.0 \mathrm{IU} / \mathrm{mL}(32.0-71.8)$ \\
\hline AST & $45.0 \mathrm{IU} / \mathrm{mL}(26.0-69.0)$ \\
\hline$\gamma \mathrm{GT}$ & $90.0 \mathrm{lU} / \mathrm{mL}(45.5-193.3)$ \\
\hline Albumin & $38.0 \mathrm{~g} / \mathrm{L}(33.5-42.5)$ \\
\hline Ferritin & $148.5 \mu \mathrm{g} / \mathrm{dL}(60.0-620.5)$ \\
\hline Creatinine & $1.03 \mathrm{mg} / \mathrm{dL}(0.94-1.42)$ \\
\hline
\end{tabular}

Abbreviations: OLT, orthotopic liver transplantation; $\mathrm{HCV}$, hepatitis $\mathrm{C}$ virus; IFN, interferon; RBV, ribavirin; SOF, sofosbuvir; SMV, simeprevir; LDV, ledipasvir; DCV, daclatasvir; 3D, paritaprevir/ritonavir with ombitasvir and dasabuvir; MELD, model for end-stage liver disease; RNA, ribonucleic acid; ALT, alanine aminotransferase; AST, aspartate aminotransferase; $\gamma$-GT, gamma-glutamyl transferase.

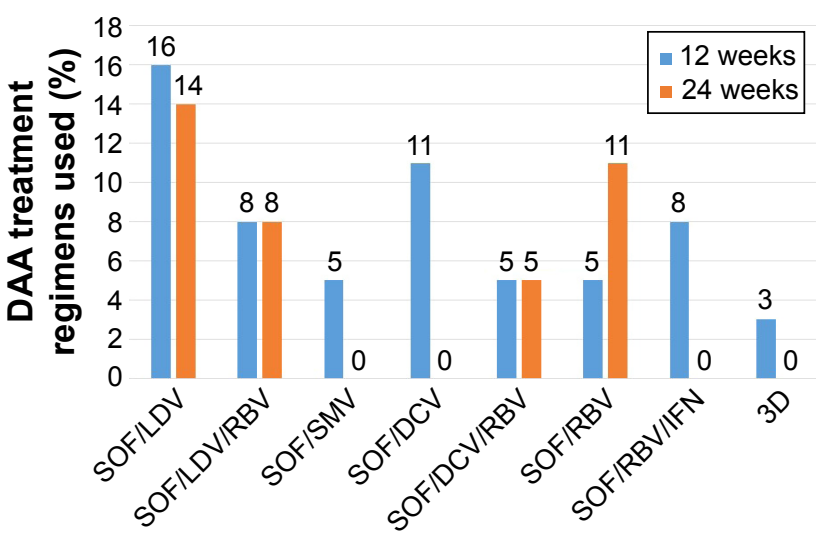

Figure 3 Therapeutic regimens sorted by treatment duration.

Abbreviations: SOF, sofosbuvir; LDV, ledipasvir; RBV, ribavirin; SMV, simeprevir; DAA, direct-acting antiviral; DCV, daclatasvir; IFN, interferon; 3D, paritaprevir/ ritonavir with ombitasvir and dasabuvir. 
A

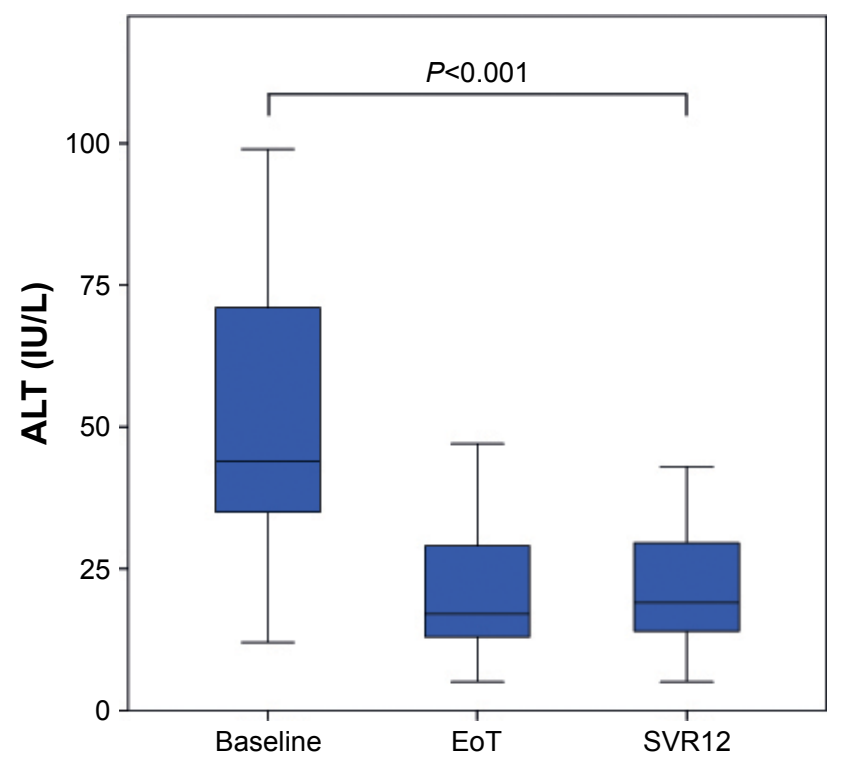

C

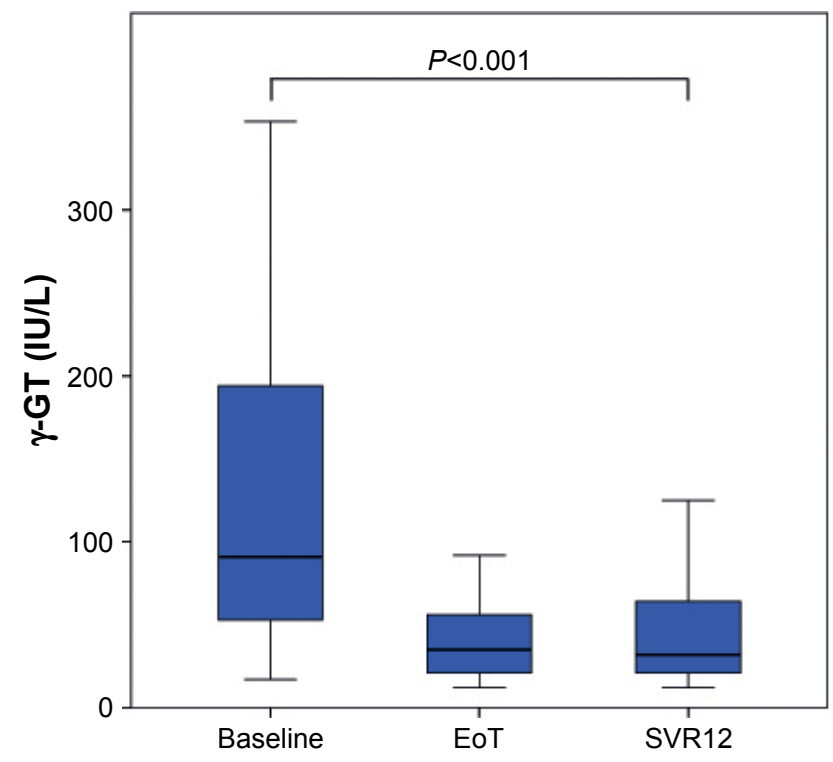

B

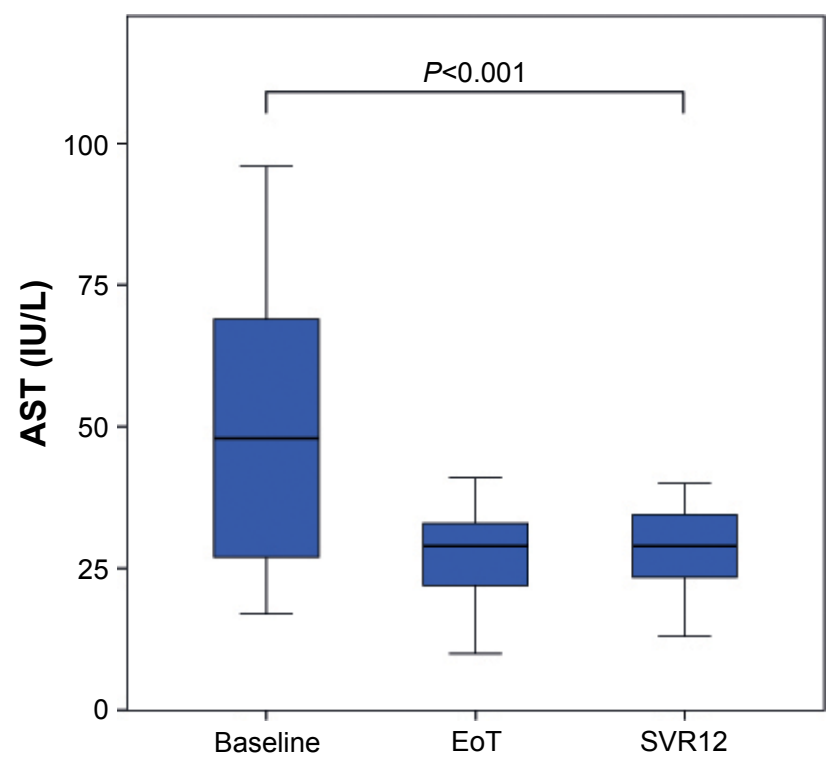

D

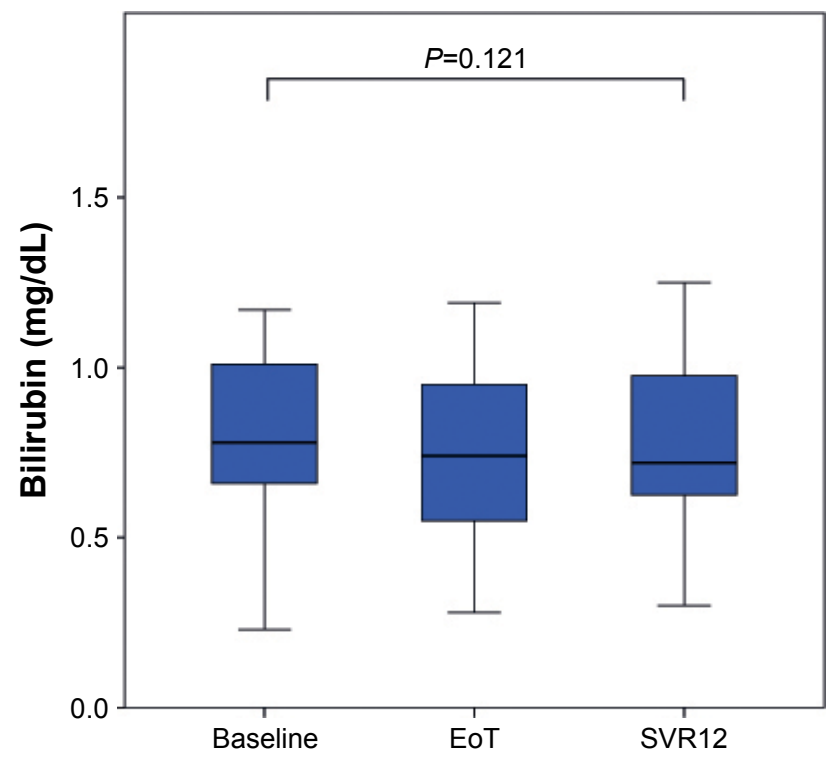

Figure 4 Biochemical response to DAA therapy. The activities of ALT (A), AST (B), $\gamma$-GT (C), and the serum levels of total bilirubin (D) declined within the observation period.

Abbreviations: ALT, alanine aminotransferase; AST, aspartate aminotransferase; DAA, direct-acting antiviral; $\gamma$-GT, gamma-glutamyl transferase; EoT, end of treatment; SVRI2, sustained virological response 12 weeks after EoT.

and gamma-glutamyl transferase $(\gamma-\mathrm{GT} ; 88.0-31.5 \mathrm{IU} / \mathrm{L})$ declined significantly from baseline to SVR12 $(P<0.001)$. Liver function tests were normal during DAA therapy. Total bilirubin decreased within the reference range from $0.78 \mathrm{mg} / \mathrm{dL}$ to $0.72 \mathrm{mg} / \mathrm{dL}$, without any statistical significance $(P=0.121)$. Albumin and $\mathrm{Hb}$ levels did not show any significant changes during the observation period $(P=0.715$ and $P=0.736$, respectively) but the values were within normal ranges at every time point.

\section{Side effects}

Side effects, especially RBV-induced anemia, are a relevant problem after LT. Anemia was common in our cohort $(32.4 \%, n=12)$. Analysis of anemic patients showed that in the majority $(83.3 \%, n=10)$ of cases, anemia was caused by RBV. From week 0 to EoT, the $\mathrm{Hb}$ level fell by a median value of $1.7 \mathrm{mg} / \mathrm{dL}$, but not $<9.5 \mathrm{mg} / \mathrm{dL}$ at any time point. No erythropoietin or transfusions were required. No acute rejection episode occurred during the observation period. Recipients 
suffered from mild fatigue $(27 \%, \mathrm{n}=10)$ and gastrointestinal disorders, especially mild nausea $(27 \%, n=10)$.

One patient with stage 3 renal failure had to discontinue DAA treatment with SOF and LDV, because of increasing creatinine values at week 17, from planned 24 weeks of therapy. Nevertheless, this patient reached SVR12.

After DAA treatment, only one patient died from rapid extrahepatic HCC recurrence with multiple metastases. Thus, a survey of survival is not possible at the moment because long-term follow-up data for DAA-treated patients is missing.

\section{Discussion}

$\mathrm{HCV}$ recurrence after LT is a major problem as it accelerates liver damage, and a significant proportion of patients develop recurrent cirrhosis within a few years after LT. 5,27,28 Therefore, $\mathrm{HCV}$-infected recipients urgently need antiviral therapy, especially in case of advanced fibrosis or cirrhosis.

In accordance with previous findings, we show that overall survival after LT is significantly worse in HCVpositive individuals. ${ }^{29}$ Moreover, patients with HCV GT1 have a significantly worse survival when compared to other HCV genotypes. Reasons for this finding are the different SVR rates by IFN therapy in GT1 vs GT2 and GT3 patients (15\% vs $57.1 \%$ and $64.7 \%$ ). GT is one of the most important predictors of a successful therapy. Many of our patients had no therapeutic option after the first or second inefficient IFN treatment until the approval of DAAs.

Nowadays, SVR rates with DAA-containing regimens are promising and will lead to a significant reduction in morbidity and mortality before and after LT, but long-term follow-up data are missing. ${ }^{30}$

In our previous hard-to-treat cohort, total SVR rate was $94.6 \%$. This is an impressive rate in a real-world post-LT cohort, especially in contrast to IFN-based regimens, where only $23.9 \%$ (27/113) pretreated LT recipients in our center achieved SVR with the combination therapy of PEG-IFN and RBV. Under DAA therapy, there were only two patients with relapse (one patient with GT1 and one patient with GT3). Both patients were male, one (GT3) suffered from rapid extrahepatic HCC recurrence with multiple metastases and died a few weeks after EoT. The second patient (GT1) failed five former IFN-based therapies and will receive another DAA regimen after resistance testing. Our data are in accordance with the results from clinical trials in the pre- and post-LT setting. ${ }^{31-34}$

Other studies in non-transplant patients have found that the response to previous IFN therapies and GT remain the most important predictive factors of SVR. ${ }^{35-37}$ Remarkably, patients who previously failed HCV therapy attained very high SVR rates (27/28 patients, $96.4 \%)$ by DAA treatment. New DAA regimens cured pretreated HCV-infected LT recipients, who were hard to treat in the past, and who had no treatment options, with a high mortality. Thus, the response and outcome of previous PEG-IFN therapy seems to be no longer an important predictive factor under DAAs for the outcome of antiviral retreatment, after prior treatment failure in this cohort. ${ }^{35,36}$

The DAAs were highly effective in all genotypes. There was no significant difference between GTs in this cohort $(P=0.932)$, possibly due to the limited number of GT3 patients with advanced fibrosis or cirrhosis: $96 \%$ of GT1, $87.5 \%$ of GT3, and all patients with GT2/4/5 reached SVR.

Therefore, all patients after LT should be treated immediately to prevent recurrent hepatitis $\mathrm{C}$ and fibrosis progression, independent of previous IFN-based therapies or GT.

The liver enzymes (ALT, AST, and $\gamma$-GT) rapidly normalized under DAA treatment $(P<0,001)$, providing evidence for the improvement in chronic hepatic inflammation and liver function.

Severe side effects were a frequent problem in $\mathrm{HCV}$ treatment during IFN therapy, especially severe RBV-induced anemia, with high rates of discontinuation. ${ }^{38,39}$ In our cohort, there was also a high rate of anemia under DAA therapy, since 10/12 patients developed anemia from RBV. In most cases, anemia was mild to moderate without a need for transfusions or therapy discontinuation. Hb levels declined by a median value of $1.7 \mathrm{mg} / \mathrm{dL}$ and no patient showed values below $9.5 \mathrm{mg} / \mathrm{dL}$. Higher rates of anemia by addition of RBV were also found by other investigators. ${ }^{17}$ Main side effects of new DAA treatment regimens in our real-life cohort were fatigue and gastrointestinal disorders in up to $27 \%$ of patients, with mild severity. This is in line with data from studies that report similar adverse events but partially higher rates of anemia. ${ }^{32,40-43}$ One patient who discontinued therapy presented with kidney failure and hepatic decompensation from recurrent cirrhosis in week 17 (from 24 weeks). This patient had undetectable HCV-RNA during follow-up and reached SVR12. Therefore, no patient failed SVR due to adverse events. In our cohort, new DAA regimens were highly effective, safe, and well tolerated by LT recipients.

Limitations of this study were the small number of patients treated with DAAs, especially in non-GT1 infections, and the monocentric design. Patients were treated according to the recommendations on treatment of hepatitis $\mathrm{C}$ of the EASL in the version of 2014 and 2015, but not to a defined 
protocol. Our data need to be confirmed by multicenter studies with a high number of patients. Follow-up data after DAA therapy are needed to investigate changes in morbidity and mortality.

\section{Conclusion}

In conclusion, this real-world cohort of HCV-infected LT recipients shows that therapy with new DAAs results in high SVR rates. The new DAA regimens will allow us to cure previously hard-to-treat LT patients with former therapeutic nihilism. Our data provide evidence for high efficacy and safety with low rates of side effects in the complex setting after LT. The necessity of addition of RBV in this cohort needs to be investigated by future studies. This clinical real-world data confirms Phase III trials from the non-transplant setting, demonstrating that DAA therapy is highly effective and safe.

\section{Acknowledgment}

We thank Anca Zimmermann, First Department of Internal Medicine, for critical review of the manuscript.

\section{Disclosure}

TZ received lecturer and consultant fees and/or travel support from AbbVie, Astellas, Bristol-Myers-Squibb, Boehringer Ingelheim, Gilead Sciences, Janssen Pharmaceuticals, MSD, Novartis, and Roche. The other authors report no conflicts of interest in this work.

\section{References}

1. Lavanchy D. The global burden of hepatitis C. Liver Int. 2009; (29 Suppl 1):74-81.

2. Perz JF, Armstrong GL, Farrington LA, Hutin YJ, Bell BP. The contributions of hepatitis B virus and hepatitis $\mathrm{C}$ virus infections to cirrhosis and primary liver cancer worldwide. J Hepatol. 2006;45(4): 529-538.

3. Carbone M, Lenci I, Baiocchi L. Prevention of hepatitis C recurrence after liver transplantation: an update. World J Gastrointest Pharmacol Ther. 2012;3(4):36-48.

4. Akamatsu N, Sugawara Y. Liver transplantation and hepatitis C. Int J Hepatol. 2012;2012:686135.

5. Garcia-Retortillo M, Forns X, Feliu A, et al. Hepatitis C virus kinetics during and immediately after liver transplantation. Hepatology. 2002; 35(3):680-687.

6. Berenguer M, Prieto M, San Juan F, et al. Contribution of donor age to the recent decrease in patient survival among $\mathrm{HCV}$-infected liver transplant recipients. Hepatology. 2002;36(1):202-210.

7. Berenguer M. Natural history of recurrent hepatitis C. Liver Transpl. 2002;8(10 Suppl 1):S14-S18.

8. Berenguer M, Prieto M, Rayon JM, et al. Natural history of clinically compensated hepatitis $\mathrm{C}$ virus-related graft cirrhosis after liver transplantation. Hepatology. 2000;32(4 Pt 1):852-858.

9. Forman LM, Lewis JD, Berlin JA, Feldman HI, Lucey MR. The association between hepatitis $\mathrm{C}$ infection and survival after orthotopic liver transplantation. Gastroenterology. 2002;122(4):889-896.
10. Ghabril M, Dickson R, Wiesner R. Improving outcomes of liver retransplantation: an analysis of trends and the impact of hepatitis $\mathrm{C}$ infection. Am J Transplant. 2008;8(2):404-411.

11. Roche B, Samuel D. Risk factors for hepatitis C recurrence after liver transplantation. J Viral Hepat. 2007;(14 Suppl 1):89-96.

12. Berenguer M, Palau A, Aguilera V, Rayon JM, Juan FS, Prieto M. Clinical benefits of antiviral therapy in patients with recurrent hepatitis $\mathrm{C}$ following liver transplantation. Am J Transplant. 2008;8(3):679-687.

13. Lawitz E, Lalezari JP, Hassanein T, et al. Sofosbuvir in combination with peginterferon alfa-2a and ribavirin for non-cirrhotic, treatment-naive patients with genotypes 1,2 , and 3 hepatitis $C$ infection: a randomised, double-blind, phase 2 trial. Lancet Infect Dis. 2013;13(5):401-408.

14. Lawitz E, Sulkowski MS, Ghalib R, et al. Simeprevir plus sofosbuvir, with or without ribavirin, to treat chronic infection with hepatitis $\mathrm{C}$ virus genotype 1 in non-responders to pegylated interferon and ribavirin and treatment-naive patients: the COSMOS randomised study. Lancet. 2014;384(9956):1756-1765

15. Burra P, Zanetto A. Filling the gap between clinical trials and real life in the treatment of severe HCV recurrence after liver transplantation. Transpl Int. 2017;30(3):239-242.

16. Herzer K, Welzel TM, Spengler U, et al. Real-world experience with daclatasvir plus sofosbuvir \pm ribavirin for post-liver transplant $\mathrm{HCV}$ recurrence and severe liver disease. Transpl Int. 2016;30(3):243-255.

17. Ciesek S, Proske V, Otto B, et al. Efficacy and safety of sofosbuvir/ ledipasvir for the treatment of patients with hepatitis $\mathrm{C}$ virus re-infection after liver transplantation. Transpl Infect Dis. 2016;18(3):326-332.

18. Maria C, Michael S, Susanne C, Catarina S, Ola W. INF-free sofosbuvirbased treatment of post-transplant hepatitis C relapse - a Swedish real life experience. Scand J Gastroenterol. 2017;52(5):585-588.

19. Berenguer M, Aguilera V, Prieto M, et al. Worse recent efficacy of antiviral therapy in liver transplant recipients with recurrent hepatitis $\mathrm{C}$ : impact of donor age and baseline cirrhosis. Liver Transpl. 2009;15(7): 738-746.

20. Wiesner RH, Sorrell M, Villamil F; International Liver Transplantation Society Expert Panel. Report of the first International Liver Transplantation Society expert panel consensus conference on liver transplantation and hepatitis C. Liver Transpl. 2003;9(11):S1-S9.

21. Berenguer M, Palau A, Fernandez A, et al. Efficacy, predictors of response, and potential risks associated with antiviral therapy in liver transplant recipients with recurrent hepatitis C. Liver Transpl. 2006;12(7): 1067-1076.

22. Kornberg A, Kupper B, Tannapfel A, Thrum K, Barthel E, Settmacher U. Antiviral treatment withdrawal in viremic $\mathrm{HCV}$-positive liver transplant patients: impact on viral loads, allograft function and morphology. Liver Int. 2006;26(7):811-816.

23. Ghany MG, Nelson DR, Strader DB, Thomas DL, Seeff LB; American Association for Study of Liver D. An update on treatment of genotype 1 chronic hepatitis $\mathrm{C}$ virus infection: 2011 practice guideline by the American Association for the Study of Liver Diseases. Hepatology. 2011;54(4):1433-1444.

24. Zimmermann T, Beckebaum S, Berg C, et al. [Expert recommendations: hepatitis C and transplantation]. Z Gastroenterol. 2016;54(7): 665-684. German.

25. European Association for Study of Liver. EASL recommendations on treatment of hepatitis C 2014. J Hepatol. 2014;61(2):373-395.

26. European Association for Study of Liver. EASL recommendations on treatment of hepatitis C 2015. J Hepatol. 2015;63(1):199-236.

27. Carrion JA, Navasa M, Garcia-Retortillo M, et al. Efficacy of antiviral therapy on hepatitis $\mathrm{C}$ recurrence after liver transplantation: a randomized controlled study. Gastroenterology. 2007;132(5):1746-1756.

28. Prieto M, Berenguer M, Rayon JM, et al. High incidence of allograft cirrhosis in hepatitis $\mathrm{C}$ virus genotype $1 \mathrm{~b}$ infection following transplantation: relationship with rejection episodes. Hepatology. 1999;29(1): $250-256$.

29. Zimmermann T, Otto C, Hoppe-Lotichius M, et al. Risk factors in patients with rapid recurrent hepatitis $\mathrm{C}$ virus-related cirrhosis within 1 year after liver transplantation. Transplant Proc. 2009;41(6):2549-2556. 
30. Willemse SB, Razavi-Shearer D, Zuure FR, et al. The estimated future disease burden of hepatitis $\mathrm{C}$ virus in the Netherlands with different treatment paradigms. Neth J Med. 2015;73(9):417-431.

31. Charlton M, Everson GT, Flamm SL, et al. Ledipasvir and sofosbuvir plus ribavirin for treatment of HCV infection in patients with advanced liver disease. Gastroenterology. 2015;149(3):649-659.

32. Charlton M, Gane E, Manns MP, et al. Sofosbuvir and ribavirin for treatment of compensated recurrent hepatitis $\mathrm{C}$ virus infection after liver transplantation. Gastroenterology. 2015;148(1):108-117.

33. Manns M, Forns X, Samuel D, et al. G02: Ledipasvir/sofosbuvir with ribavirin is safe and efficacious in decompensated and post liver transplantation patients with $\mathrm{HCV}$ infection: preliminary results of the prospective solar 2 trial. J Hepatol. 2015;62(Suppl 2):S187-S188.

34. Saxena V, Terrault N. Current management of hepatitis $\mathrm{C}$ virus: regimens for peri-liver transplant patients. Clin Liver Dis. 2015;19(4): 669-688, vi.

35. Bacon BR, Gordon SC, Lawitz E, et al; HCV RESPOND-2 Investigators. Boceprevir for previously treated chronic HCV genotype 1 infection. N Engl J Med. 2011;364(13):1207-1217.

36. Zeuzem S, Andreone P, Pol S, et al; REALIZE Study Team. Telaprevir for retreatment of HCV infection. $N$ Engl J Med. 2011;364(25): 2417-2428.

37. Zeuzem S, Mensa FJ. Concordance between SVR12and SVR24 in genotype $1 \mathrm{HCV}$ patients receiving interferon-free treatment in the SOUND-C2 study. Hepatology. 2013;58(4):1516.
38. Coilly A, Fougerou-Leurent C, de Ledinghen V, et al; ANRS C023 CUPILT Study Group. Multicentre experience using daclatasvir and sofosbuvir to treat hepatitis C recurrence - the ANRS CUPILT study. J Hepatol. 2016;65(4):711-718.

39. Dumortier J, Leroy V, Duvoux C, et al. Sofosbuvir-based treatment of hepatitis $\mathrm{C}$ with severe fibrosis (METAVIR F3/F4) after liver transplantation. Liver Transpl. 2016;22(10):1367-1378.

40. Welzel TM, Nelson DR, Morelli G, et al; HCV-TARGET Study Group. Effectiveness and safety of sofosbuvir plus ribavirin for the treatment of HCV genotype 2 infection: results of the real-world, clinical practice HCV-TARGET study. Gut. 2016;pii: gutjnl-2016-311609.

41. Kwo PY, Mantry PS, Coakley E, et al. An interferon-free antiviral regimen for HCV after liver transplantation. $N$ Engl J Med. 2014;371(25): 2375-2382.

42. Pungpapong S, Aqel B, Leise M, et al. Multicenter experience using simeprevir and sofosbuvir with or without ribavirin to treat hepatitis C genotype 1 after liver transplant. Hepatology. 2015;61(6):1880-1886.

43. Roth D, Nelson DR, Bruchfeld A, et al. Grazoprevir plus elbasvir in treatment-naive and treatment-experienced patients with hepatitis $\mathrm{C}$ virus genotype 1 infection and stage 4-5 chronic kidney disease (the C-SURFER study): a combination phase 3 study. Lancet. 2015;386(10003): p1537-p1545.
Drug Design, Development and Therapy

\section{Publish your work in this journal}

Drug Design, Development and Therapy is an international, peerreviewed open-access journal that spans the spectrum of drug design and development through to clinical applications. Clinical outcomes, patient safety, and programs for the development and effective, safe, and sustained use of medicines are the features of the journal, which

\section{Dovepress}

has also been accepted for indexing on PubMed Central. The manuscript management system is completely online and includes a very quick and fair peer-review system, which is all easy to use. Visit http://www.dovepress.com/testimonials.php to read real quotes from published authors. 